\title{
Anterior-Only Approach for Posttraumatic Subaxial Cervical Spine Spondyloptosis: A Case Report and Review of Literature
}

\author{
Raj Kumar $^{1}$ Suyash Singh ${ }^{1}$ Kuntal Kanti Das ${ }^{1} \quad$ Arushi Kumar $^{2}$ \\ 1Department of Neurosurgery, SGPGIMS, Lucknow, \\ Uttar Pradesh, India \\ 2Department of Pathology, SGPGIMS, Lucknow, Uttar Pradesh, India \\ Address for correspondence Raj Kumar, MS, Mch, Department \\ of Neurosurgery, SGPGIMS, Lucknow, Uttar Pradesh, India \\ (e-mail: rajkumar1959@gmail.com).
}

Indian J Neurosurg 2019;8:69-72
Abstract
Keywords
- anterior-only approach
- posttraumatic subaxi- al spondyloptosis
- spastic quadriparesis

Subaxial posttraumatic spondyloptosis is a rare entity with management dilemma in the literature. Various approaches have been discussed, but few reports focused on management plan and rationale. The authors reviewed the literature and reported a case of a 30-year-old woman presented with posttraumatic spastic quadriparesis. The patient had C6-7 spondyloptosis and was operated by anterior-only approach. There was improvement in both motor and sensory neurologic status. Surgical goals include vertebral realignment and stabilization. The authors conclude that anterior approach may be good enough if performed properly even if all three columns are involved.

\section{Introduction}

Posttraumatic subaxial cervical spondyloptosis is an uncommon injury with controversial management options. The disruption of all three columns renders spine unstable with severe cord trauma. Enthusiastic approaches have been described in the literature, but there is no clinical trial or randomized study comparing outcomes on anterior- or posterior-only or combined approaches. The combined approach provides the most stable construct but takes longer operative time and various risks of turning patient from prone to supine position. Considering the paucity, hereby we reviewed the literature and reported a case of posttraumatic C6-7 spondyloptosis associated with spastic quadriparesis treated with an anterior-only approach.

\section{Case Summary}

A 30-year-old housewife fell down the stairs from the second floor of a building, approximately 20 feet, and was admitted at our hospital 10 months later. Initially, she was being managed at primary and secondary care centers on traction. She had quadriparesis with the American Spinal Injury Association (ASIA) and Frankel grades $C$ that kept deteriorating. She had spastic quadriparesis since the fall along with tingling paresthesias and cervical pain. Tone was increased in all four

received

January 5, 2018

accepted

DOI https://doi.org/

$10.1055 /$ s-0039-1677963

April 4, 2018

ISSN 2277-954X. limbs, and deep tendon reflexes were exaggerated at the biceps, triceps, knee, and ankle. Power was 0/5 MRC (Medical Research Council) grade distally to $2-3 / 5$ proximally in both the upper and lower limbs. She had $60 \%$ impairment for all modalities of sensations below $\mathrm{C7}$ dermatome. The computed tomography (CT) scan showed C6-7 spondyloptosis with all three columns involved. The laminae and facets of C6-7 were fractured ( $\boldsymbol{- \text { Fig. }} \mathbf{1})$. Magnetic resonance imaging (MRI) showed compression of the spinal cord along with cord intensity changes, and the cord has taken S shape with C6 body almost lying ventral to $\mathrm{C} 7$ body. Initially Gardner-Wells traction was applied in incremental weights from 2.5 to $5 \mathrm{~kg}$, but no improvement occurred after 1 week. Taking consideration of anterior compression of the cord, anterior approach was planned to avoid double operation. The patient was operated upon anteriorly with traction intraoperatively. Intraoperatively the cord was severely compressed. We found slight difficulty due to deep plane of surgery at the level of listhesis. A central corpectomy of C6 and C7 vertebrae was done through a low right-sided anterior neck incision. Dura was so much compressed with vertebral body that there was an inadvertent tear at lower part of exposure. The tear was managed primarily with fat and glue, and cord pulsations could be appreciated thereafter. A C7-T1 discectomy and anterior fusion of C5-T1 using an integrated with allograft were performed, and a titanium-expandable cage and bone 


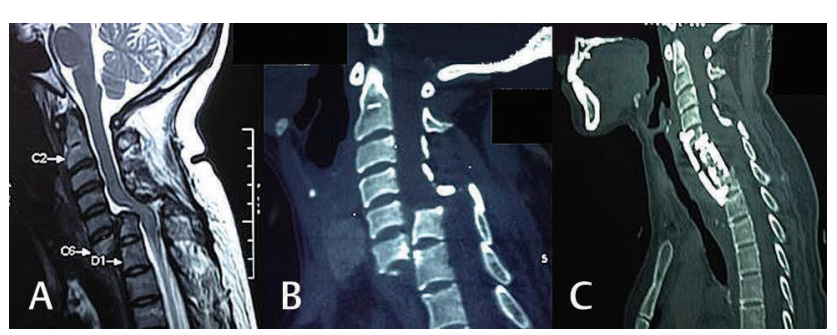

Fig. 1 (A) Magnetic resonance imaging sagittal sequence showing compression of spinal cord along with cord intensity changes, and cord has taken $\mathrm{S}$ shaped with $\mathrm{C} 6$ body almost lying ventral to $\mathrm{C} 7$ body. (B) Preoperative computed tomography showing high-grade listhesis C6 over C7 and C6 body almost came ventral to C7. (C) Postoperative computed tomography showing that C7-T1 discectomy and anterior fusion of $\mathrm{C} 5-\mathrm{T} 1$ using an integrated with allograft were performed and a titanium-expandable cage with normal alignment of vertebral bodies and increased spinal canal diameter at the same level.

chips within were inserted. We found that even after extensive decompression, the plane of $\mathrm{C} 5$ and $\mathrm{T} 1$ vertebral body was discordant. A gutter was created on distal part of $\mathrm{C5}$ vertebra and proximal endplate of $\mathrm{T} 1$ body where our titanium plate could be snugly fitted. The patient was extubated on postoperative day 1 . An immediate postoperative X-ray confirmed the position of the graft. There was improvement in power and tone postoperatively, and the patient was discharged on postoperative day 5 ( - Fig. 2 ).

\section{Discussion}

Lack of proper guideline leaves certain important questions unanswered. The questions include the following; (1) At what time traction should be applied and till when it should be continued? (2) What are the indications of taking anterior, posterior, or combined corridors? (3) If combined corridor is taken, which should be done first? (4) Will the approach differ if patient presents relatively asymptomatically?

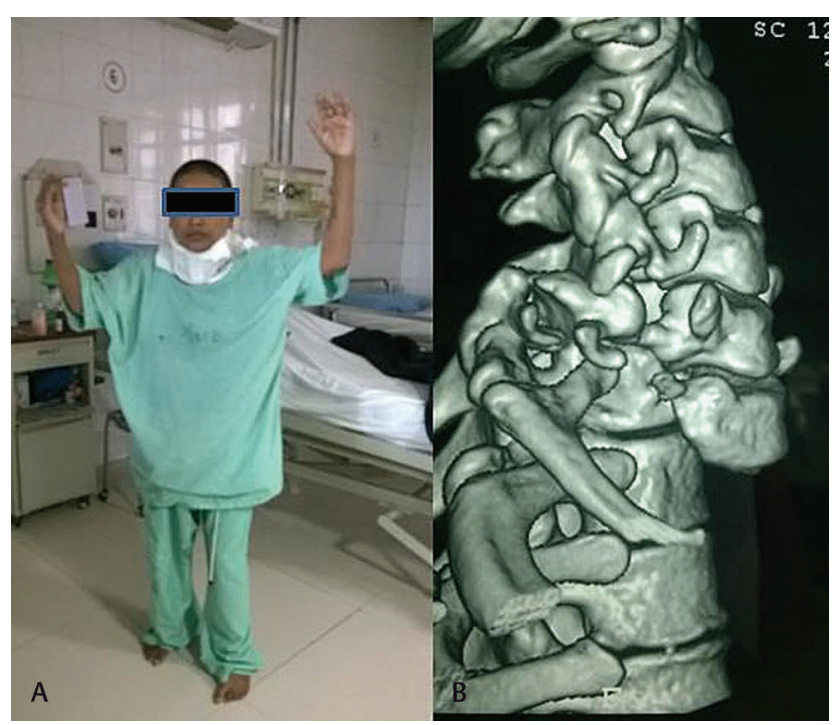

Fig. 2 (A) Clinical postoperative photograph of patient in improved status. (B) Three-dimensional preoperative computed tomography showing high-grade listhesis $\mathrm{C} 6$ over $\mathrm{C} 7$.
The abrupt transition from a mobile segment to relatively fix segment makes certain levels of spine more prone for high-grade listhesis. These levels include cervicothoracic and lumbosacral junctions. The cervicothoracic junction has transition from the lordotic mobile cervical spine to the more rigid kyphotic thoracic spine. The subaxial cervical spine spondyloptosis is rare and demands high surgical skills. Cervical spondyloptosis typically results from severe hyperextension or hyperflexion-compression injury with bilateral pedicle fractures, and bilateral locked facets, with or without fracture of the laminae. ${ }^{1}$ These injuries are usually associated with complete and irreversible spinal cord injury. Sometimes fracture of the posterior elements can lead to a spontaneous decompression of the spinal canal and thereby preserve the spinal cord by the cord moving posterior.

\section{Closed Reduction as an Initial Treatment}

An immediate closed reduction should be done even before cervical MRI followed by definitive plan. Role of cervical traction in cases with partial neurologic deficit is still controversial. Up to $70 \%$ of the cervical fractures can be realigned with traction., ${ }^{2,3}$

Menku et al suggested that retropulsion of the disc into the spinal canal during traction could lead to compression of the spinal cord and cause neurologic deterioration. ${ }^{2}$ Serial plain film X-rays are needed with sequentially increasing the amount of weight used for reduction. Patients showing reduction or unlocking of facets joint may be offered anterior approach. Any deterioration in neurologic status prompts one to remove traction and look for associated atlanto-occipital dislocation. Traction reestablishes normal spinal alignment and helps initial decompression of the spinal cord. ${ }^{4}$ Some authors suggest application of traction in the conscious patient even if status of intervertebral disc in unknown. ${ }^{5}$ On further evaluation, if intervertebral disc is involved, anterior approach is preferred.

\section{Timing of Intervention}

Timing of surgery is under debate. While some authors argue that early operation is associated with significant morbidity due to a retropulsed disc, others believe that early intervention is not associated with a higher incidence of complications. ${ }^{6}$

It is obvious that application of traction will delay surgical decompression. One school of thought favoring early decompression believes that nearly 60 to $70 \%$ improvement can occur if the patient is operated upon within 6 hours. We believe that decision should be individualized to general clinical status of the patient including status of polytrauma and evidence-based practice to predict the best outcome. We believe that initiating management with closed reduction policy might avoid the need of posterior decompression.?

\section{Biomechanics}

In the subaxial spine, ligaments and muscular posterior band play a major role in providing stability. The maximal sagittal plane translation occurring under physiologic loads is 2 to $2.7 \mathrm{~mm} .{ }^{8}$ Cervical spondyloptosis is a type of compressive 
extension five-stage injury. There is bilateral vertebral arch fracture along with ligamentous complex disruption leading to translation of one vertebral body onto other. This leads to high degree of trauma to the spinal cord. Although various cases are reported stating sparing of the cord, there was severe compression in our case. The cord was compressed between the anterior vertebral body of the inferior vertebra and posterior elements.

\section{Surgical Approaches}

Surgical management of high-grade subaxial cervical spine injury can be divided into three groups:

\section{Anterior}

2. Posterior

3. Combined anterior and posterior, that is, 360 degrees

Wong and colleagues described a similar case of C5-6 spondyloptosis that was managed by anterior-only approach. In the follow-up of 6 months, the neurologic condition of the patient remained the same. He reviewed the literature and found no significant difference between the anterioronly, posterior-only, and 360-degree repair groups regarding immediate postoperative ASIA grade and also in ASIA grade at the end of the follow-up period..$^{9}$ In our case, there was improvement in both motor and sensory parameters. We believe that the extent of decompression was key factor in our case leading to dramatic recovery.

Bhojraj and Shahane suggested that closed reduction followed by limited anterior-only fusion supplemented by rigid postoperative immobilization is safer and more effective than combined fusion..$^{10}$ We agree with his statement partly that closed reduction is an important initial management, but we believe that a rigid immobilization is not necessary if intraoperative construct is placed strong enough to stabilize the spine. We rather believe in early mobilization as in our case that was discharged on fifth day.

Cho et al also reported a case of C6-7 spondyloptosis. They fused the segment posteriorly first and found that despite performing posterior decompression and fixation, the stability could not be attained. The ruptured C6-7 intervertebral disc was viewed on follow-up MRI, and the C6-7 body structure was still compressing the spinal cord. The report emphasizes on a strong point that if disc prolapsed is present along with bony listhesis, one should go directly from anterior side. The posterior approach is rather difficult in these cases.

In combined approach, it is matter of debate that which step should be taken first. Proponent of anterior first approach $^{11,12}$ says that the approach provides stabilization in cases with significant disc herniation and prevent the risk of additional trauma in case of turning the patient on the operation table for the posterior approach. In a retrospective analysis of high-grade spondylolisthesis, Sribnick et al found the combined approach as the best treatment option available. ${ }^{12}$ In his review, he used multisegment fusion that we believe unnecessarily adds up the cost of treatment. Although the point is not so important in developed countries, in developing countries, the surgeon needs to consider economical grounds as well.
The second school of thought says that the posterior approach allows direct disengagement of the inferior facet from the superior facet. Posterior approach also prevents the risk of graft dislodgement if anterior approach is chosen initially. Ozdogan et al reported that there is a possible risk of graft dislodgment if the initial operation is done anteriorly. ${ }^{13}$ The initial approach should be decided on the basis of success or failure of closed reduction and the presence of significant disc herniation or presence of locked facets. ${ }^{14,15}$

\section{Transmanubrium Approach}

The transition from the flexible cervical spine to the relatively rigid thoracic spine obviates important changes in spinal biomechanics. First thoracic vertebra angled as normal curvature of thoracic vertebrae starts. In close proximity to major vessels and nerves, this vertebra is relatively difficult to access. The difficulty increases in view of inclined projector of screw application. Grunenwald and Spaggiari described this approach in $1997 .{ }^{16}$ Retracting sternocleidomastoid muscle is laterally followed by cartilage resection of the first rib done. Superolateral part of the first rib is divided. Medial third of clavicle can also be removed along with the creation of a window in the manubrium. Here important point is to preserve sternoclavicular articulation and insertion of sternomastoid muscle. The phrenic nerve, the 11th cranial nerve, sympathetic chain, and, on the left side, the thoracic duct should be protected. This approach provides good exposure of vessels in this region. The approach is used for cervicothoracic tumors such as neuroblastoma or tumors of the pulmonary sulcus such as Pancoast-Tobias tumor. The approach provides best exposure from $\mathrm{C} 3$ to $\mathrm{T} 5$ region. We did not use this approach because we achieved a safe corridor well above manubrium level.

Other approaches such as transclavicular, transaxillary, or trapdoor approach described in the literature for tumors of the cervicothoracic region are rarely needed for traumatic listhesis.

\section{Conclusion}

Subaxial cervical spine spondyloptosis is an uncommon injury. Surgical goals include vertebral realignment and stabilization. We conclude that anterior approach may be good enough if performed properly even if all three columns are involved. Anterior approach with decompression and fusion provides the safest surgical result. Presence of disc herniation and cord compression necessitates anterior approach.

\section{Funding}

None.

\section{Conflict of Interest}

None. 


\section{References}

1 Ramieri A, Domenicucci M, Cellocco P, Lenzi J, Dugoni DE, Costanzo G. Traumatic spondylolisthesis and spondyloptosis of the subaxial cervical spine without neurological deficits: closed re-alignment, surgical options and literature review. Eur Spine J 2014;23(Suppl 6):658-663

2 Menku A, Kurtsoy A, Tucer B, Oktem IS, Akdemir H. The surgical management of traumatic C6-C7 spondyloptosis in a patient without neurological deficits. Minim Invasive Neurosurg 2004;47(4):242-244

3 Joaquim AF, Patel AA. Subaxial cervical spine trauma: evaluation and surgical decision-making. Global Spine J 2014;4(1):63-70

4 Joint Section on Disorders of the Spine and Peripheral Nerves of the American Association of Neurological Surgeons and the Congress of Neurological Surgeons: Chapter 6: Initial closed reduction of cervical spine fracture-dislocation injuries. Guidelines for the management of acute cervical spine and spinal cord injuries. Neurosurgery 2002;50(Suppl 3):44-50

5 Feuchtbaum E, Buchowski J, Zebala L. Subaxial cervical spine trauma. Curr Rev Musculoskelet Med 2016;9(4):496-504

6 Levi L, Wolf A, Rigamonti D, Ragheb J, Mirvis S, Robinson WL. Anterior decompression in cervical spine trauma: does the timing of surgery affect the outcome? Neurosurgery $1991 ; 29(2): 216-222$

7 O'Dowd JK. Basic principles of management for cervical spine trauma. Eur Spine J 2010;19(Suppl 1):S18-S22
8 White AA III, Panjabi MM. Clinical Biomechanics of the Spine. Philadelphia, PA: J.B. Lippincott; 1978

9 Wong KE, Chang PS, Monasky MS, Samuelson RM. Traumatic spondyloptosis of the cervical spine: a case report and discussion of worldwide treatment trends. Surg Neurol Int 2017;8:89

10 Bhojraj SY, Shahane SM. Posttraumatic cervical spondyloptosis at C6-7 with late-onset cord compression: a new clinical entity. Case report. J Neurosurg 1992;77(5):792-794

11 Choi MK, Jo DJ, Kim MK, Kim TS. Management of traumatic C6-7 spondyloptosis with cord compression. J Korean Neurosurg Soc 2014;55(5):289-292

12 Sribnick EA, Hoh DJ, Dhall SS. Traumatic high-grade cervical dislocation: treatment strategies and outcomes. World Neurosurg 2014;82(6):1374-1379

13 Ozdogan C, Gogusgeren MA, Dosoglu M. Posttraumatic cervical spondyloptosis “case report.” Turk J Trauma Emerg Surg 1999;5:46-48

14 Ahn TK, Chung YS, Kim MS, Han I. High-grade traumatic spondylolisthesis of $\mathrm{C7}$ on $\mathrm{T} 1$ with no neurological deficit. Nerve 2015;1(1):37-39

15 Munakomi S, Bhattarai B, Cherian I. Traumatic cervical spondyloptosis in a neurologically stable patient: a therapeutic challenge. Case Rep Crit Care 2015;2015:540919

16 Grunenwald D, Spaggiari L. Transmanubrial osteomuscular sparing approach for apical chest tumors. Ann Thorac Surg 1997;63(2):563-566 